Centre of Excellence for Nuclear Materials

\title{
Simulation of C-Component Dislocation Loops by lons and Protons Irradiation. A Tool to Understand the Breakaway Growth of Recrystallized Zr-Based Alloys
}

\author{
Jean Paul MARDON ${ }^{1}$, Nesrine GHARBI ${ }^{2}$, Thomas JOURDAN ${ }^{3}$, Didier GILBON ${ }^{4}$, \\ Fabien ONIMUS ${ }^{2}$, Xavier FEAUGEAS ${ }^{5}$, Rosmarie HENGSTLER-EGER ${ }^{6}$ \\ ${ }^{1}$ AREVA NP, Fuel Business Unit (Lyon, France) \\ ${ }^{2}$ CEA-DEN-DMN, Service de Recherches Métallurgiques Appliquées, SRMA (Saclay, France) \\ ${ }^{3}$ CEA-DEN-DMN, Service de Recherches de Métallurgie Physique, SRMP (Saclay, France) \\ ${ }^{4}$ CEA-DEN, Department of Nuclear Materials, DMN (Saclay, France) \\ ${ }^{5}$ LaSI, University La Rochelle (La Rochelle, France) \\ ${ }^{6}$ AREVA NP, GmBH (Erlangen, Germany)
}

During normal in-service operation, the PWR fuel assemblies exhibit a macroscopic elongation. This dimensional change is the result of three different phenomena: thermal creep, irradiation-creep and irradiation growth which occurs in the absence of any applied stress. This last phenomenon, referred as stress-free growth, is related to irradiation-induced microstructural changes taking place in the hexagonal close packed grains and corresponding to an elongation along the basal plane and a shortening along the c-axis, the volume remaining constant (Fig 1). Under neutron irradiation, recrystallized $\mathrm{Zr}$-based alloys undergo stress-free growth which accelerates for high irradiation doses (Fig 2). This acceleration is correlated to specific c-component vacancy dislocation loops.

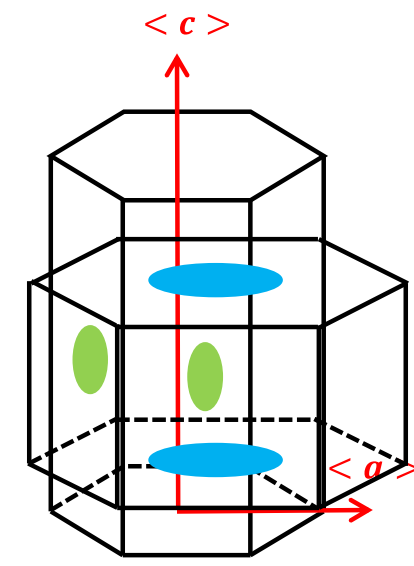

Fig. 1: Changes taking place in the hexagonal close packed grains [1]

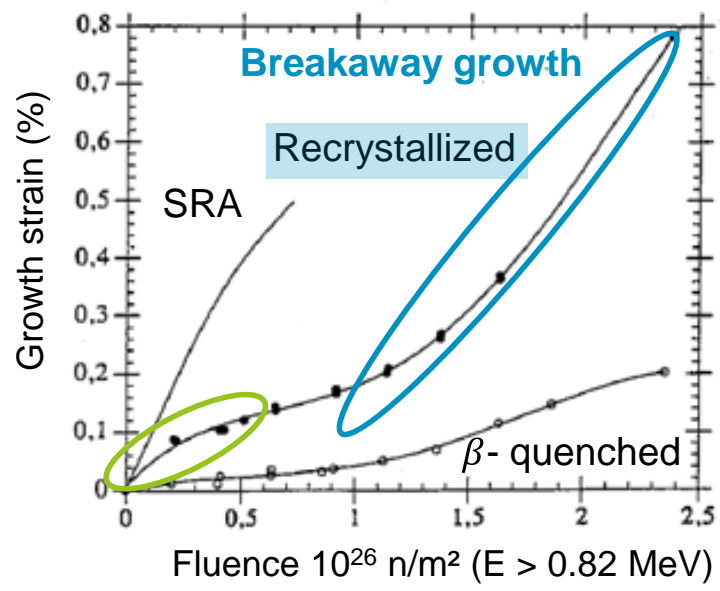

Fig. 2: Recrystallized Zr alloys breakaway growth [1]

Since these defects are responsible for the breakaway growth, which influences the performance of the fuel assembly, it is important to know the effect of various factors on their microstructure. The industrial feedback observed on some PWR fuel assemblies suggests that a macroscopic stress applied in the early life could affect the c-loop microstructure and therefore impact the subsequent stress-free growth. In addition, some feedbacks show that in-service hydrogen pick-up could also influence the fuel assembly radiation-induced deformation. In order to have a better understanding of this phenomenon, thorough analytical studies of c-loops nucleation and growth has been undertaken using charged particles irradiation. Protons and ions irradiation experiences have been carried out on various worldwide facilities at several temperatures combined with TEM exams [1, 2].

Two complementary studies were carried out to simulate neutron irradiation: in-situ tensile tests under $1 \mathrm{MeV} \mathrm{Kr}^{2+}$ ion irradiation and bending experiments under $600 \mathrm{keV} \mathrm{Zr}^{+}$ion irradiation in order to investigate the impact of a macroscopic stress applied under irradiation on the evolution of c-loop microstructure [3]. 
In-situ $\mathrm{Kr}^{2+}$ ion irradiation was performed at high dose (up to $25 \mathrm{dpa}$ ) on RXA Zircaloy-4 at $573 \mathrm{~K}$ with the stress applied from the beginning of the irradiation. We observe in few grains a clear effect of stress on the c-loop linear density (Fig 3 ).

$\mathrm{Zr}+$ ion irradiations were performed at $573 \mathrm{~K}$ on RXA Zircaloy-4 and M5® and two loading histories were considered, using a four point bending device specifically designed to apply a tensile or a compressive stress under irradiation. During the first loading experiment, the external stress was applied at an early stage of irradiation. Transmission Electron Microscopy (TEM) observations showed that the initial applied stress has no effect on the incubation dose of c-loops. For the second loading experiment, the macroscopic stress was applied when c-loops are already created. Same trend, that the one observed for in-situ experience, but with a lower effect of stress on the c-loop linear density was observed on RXA Zircaloy-4 and M5® due to dispersion from grain to grain and a much larger statistic for this experiment (Fig 4) [1]. Nevertheless, qualitative agreement between two experiments is noticed.

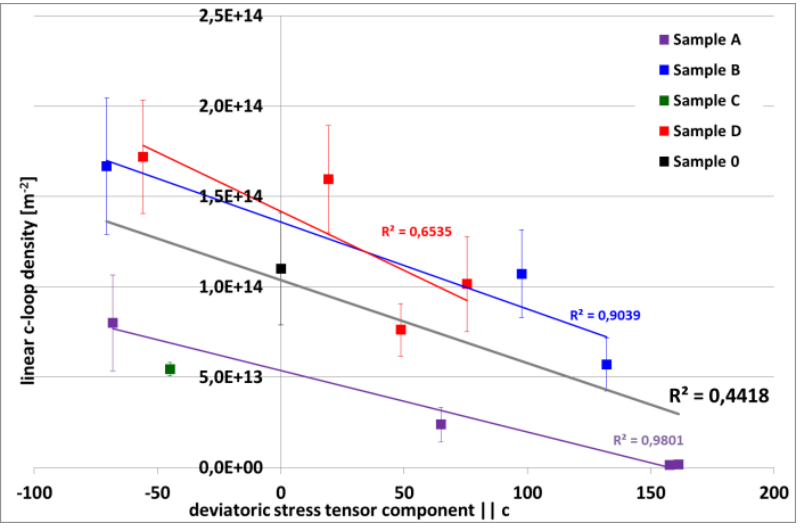

Fig. 3: Evolution of c-loops density for Zy4 (In-situ $\mathrm{Kr}^{2+}$ ion irradiation) [3]

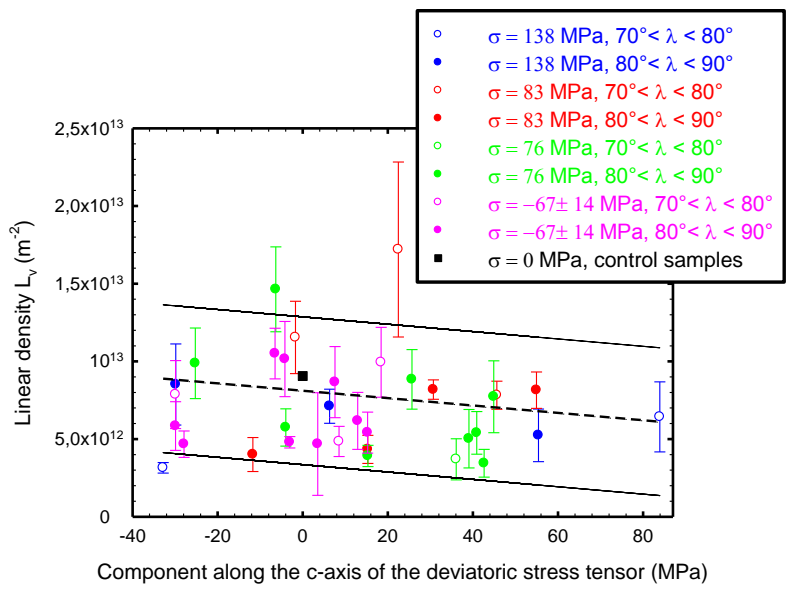

Fig. 4: Evolution of c-loops density for Zy4 (Bending $\mathrm{Zr}+$ ion irradiations) [3]

Indeed, the c-loop linear density is lower when a tensile stress is applied parallel to the c-axis, which is in good agreement with the Stress Induced Preferential Absorption (SIPA) mechanism. Based on these results under stress level below the transverse yield strength and at $573 \mathrm{~K}$, the quantitative statistical study conducted on a large number of Zircaloy-4 and $\mathrm{M} 5 \AA$ grains with different orientations of the c-axis with respect to the loading direction, shows that an externally applied stress has a slight effect on the c-loop microstructure. A trend for the evolution of their densities with the component along the c-axis of the deviatoric stress tensor was obtained and is consistent with the SIPA mechanism, but seems to be not very significant considering the dispersion from grain to grain. The average loop size is weakly affected by the applied stress and the coupling between the axial irradiation creep and the accelerated irradiation growth appears to be low at the grain scale.

\section{References}

[1] N. Gharbi, F. Onimus, D. Gilbon, J.-P. Mardon, X. Feaugas, "Impact of an applied stress on ccomponent loops under Zr ion irradiation in recrystallized Zircaloy-4 and M5 ${ }^{\circledR}$, JNM-D-15-00312 (to be published).

[2] L. Tournadre, F. Onimus, T. Jourdan, J.-P. Mardon, X. Feaugeas, "Impact of hydrogen pick-up and applied stress on c-component loops: toward a better understanding of the radiation induced growth of recrystallized zirconium alloys", ASTM STP 1453 (2014), pp. 853-893.

[3] N. Gharbi, R. M. Hengstler-Eger, X. Feaugeas, D.Gilbon, P. B. Hoffmann, M. A.Kirk, J.-P.Mardon, F. Onimus, "The effect of applied stress on C-component dislocation loops in Zr-Based alloys", TMS $144^{\text {th }}$ Annuel meeting and Exhibition, March 15-19, 2015, Orlando, USA. 
$A$

AREVA 


\section{MINDS}

\section{Simulation of c-component dislocation loops by ions and protons irradiation. A tool to understand the breakaway growth of recrystallized Zr-based alloys}

Nesrine GHARBI ${ }^{2}$, Thomas JOURDAN², Didier GILBON², Fabien ONIMUS ${ }^{2}$ ${ }^{2}$ CEA, DEN/DANS/DMN/SRMA/SRMP, 91190 Saclay, France Xavier FEAUGEAS ${ }^{3}$

${ }^{3}$ LaSI, University La Rochelle, 17000 La Rochelle, France Jean Paul MARDON1, Rosmarie Hengstler-Eger ${ }^{4}$

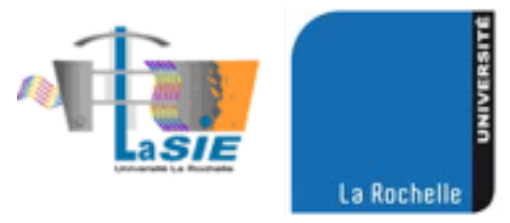

1 AREVA NP, 10 rue Juliette Récamier, 69456, Lyon Cedex 06, France

4 AREVA GmbH, Erlangen, Germany

$2^{\text {nd }}$ Int. Workshop Irradiation of Nuclear Materials: Flux and Dose November 4-6, 2015, CEA - INSTN Cadarache, France 


\section{Contents}

- Industrial feedbacks, macroscopic elongation of Zr alloys under neutron irradiation

- Simulation of <c>-component dislocation loops by using charged particles: $\mathrm{Zr}^{+}$and $\mathrm{Kr}^{+}$ions and Protons (feasibility studies)

- Impact of an external tensile and/or compressive stress on <c> loops

- Impact of in-service hydrogen pick-up on $<c>$ loops

- Conclusion 


\section{Objectives}

Prediction of the macroscopic elongation of fuel assemblies under neutron irradiation $\checkmark$

Q1: Coupling under irradiation between 'stress-free' growth and axial irradiation creep ?

Hypothesis: c-loops are responsible for the growth breakaway

Q2: How macroscopic stress and in-service hydrogen pick-up could influence the growth acceleration?

macroscopic stress applied under irradiation in-service hydrogen pick-up

2 complementary studies

1. In-situ tensile tests under $1 \mathrm{MeV} \mathrm{Kr}^{2+}$ ion irradiation

Protons irradiations

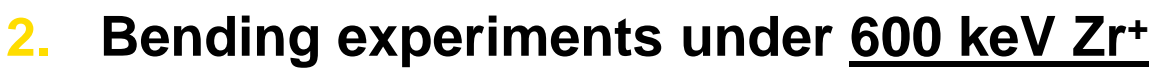
ion irradiation

Irradiation time scale

Neutron Protons

Ions

Years

Days

Hours 
Evolution of $\langle c>$ loops density vs. irradiation protons dose in Zircaloy-4 and M5® alloys

L. Tournadre (1) et al. TIMS2011
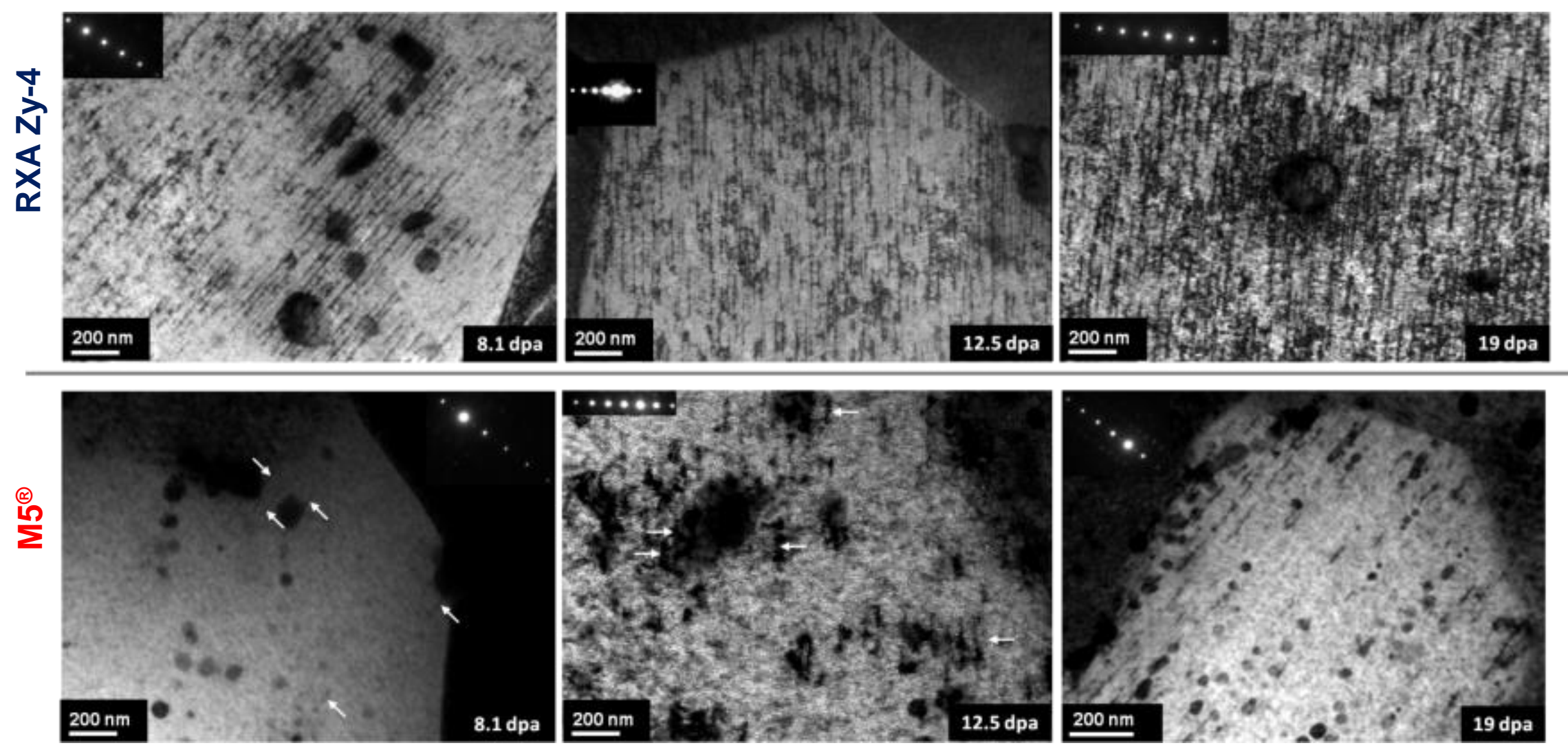

$\Longrightarrow$ Large and faulted $<c>$ loops in consistent densities with increasing dose

$\Longrightarrow$ Fewer $<$ C > loops in M5 ${ }^{\circledR}$ than in RXA Zy-4 FUEL
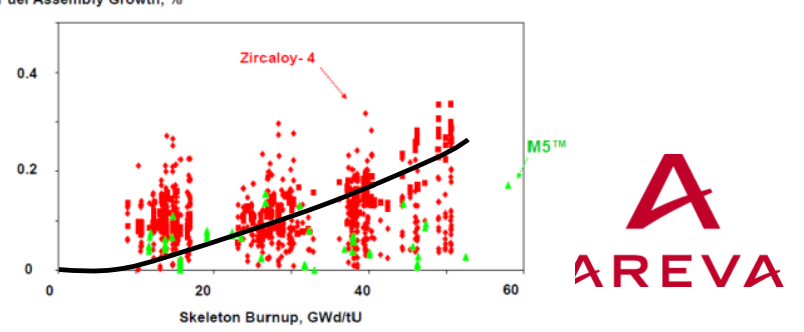
Are charged particles irradiations a good simulation of the neutron damage?
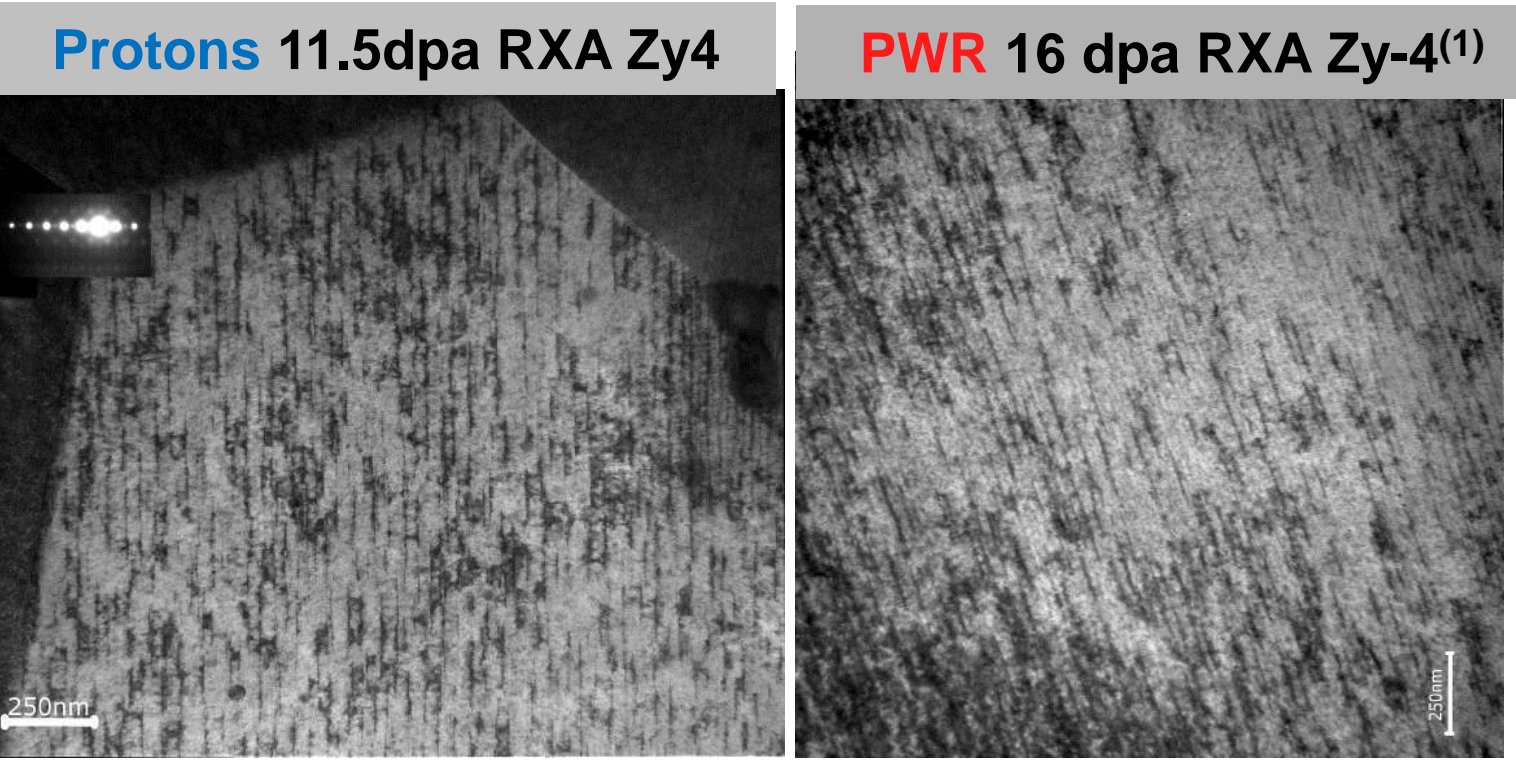

Close to neutron irradiated microstructure

$$
L_{v}=\frac{N<d>}{V}
$$

<c> loop linear density $L_{\mathrm{v}}$ evolution with irradiation dose for $\mathrm{Zy}-4$ and M5'after $2 \mathrm{MeV}$ proton irradiations at $623 \mathrm{~K}$

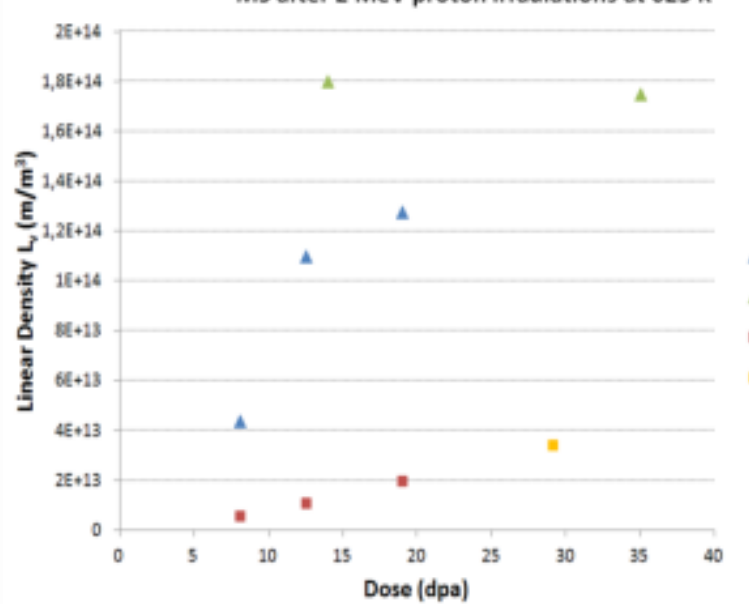

$\triangle$ RXAZZy-4 protons A RXAZY-4 neutrons - M5"protons - M5 noutrons

Densities $L_{v}$ consistent with neutron results

Charged particles irradiations (mainly Protons) are representative of PWR operating conditions

FUEL

[1] P.Bossis et al, 15 ${ }^{\text {th }}$ ASTM, 2009

[2] D.Gilbon et al, 10 ${ }^{\text {th }}$ ASTM, 1994 


\section{Studied materials}

Recrystallized Zircaloy-4 and M5 ${ }^{{ }^{*}}$

\begin{tabular}{|c|ccccc|}
\hline Element (wt\%) & Sn & No & Fe & Cr & 0 \\
RXA Zy-4 & $\sim 1.30$ & - & 0.22 & 0.11 & 0.13 \\
\hdashline M5 $^{\oplus}$ & - & 1.00 & $0.035-0.040$ & - & 0.14 \\
\hline
\end{tabular}

Samples taken in the (TD, RD) plane of an intermediate product: TREX

Tube of $\sim 11 \mathrm{~mm}$ thick

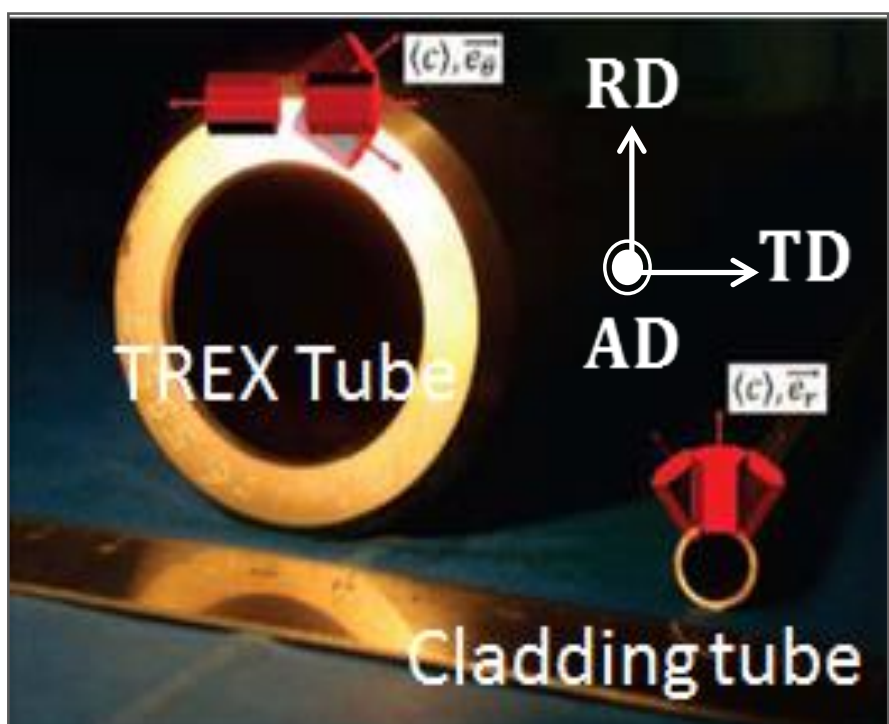

FUEL

Transverse texture

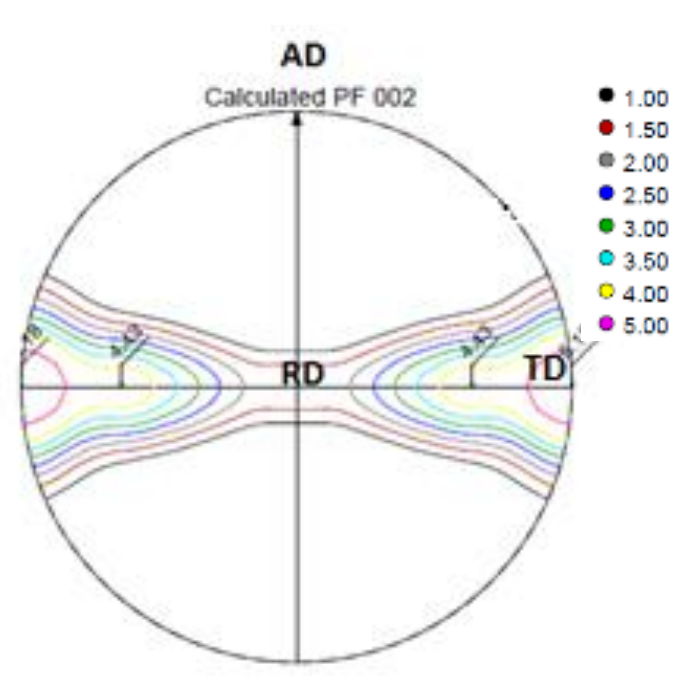

(0002) Pole figure

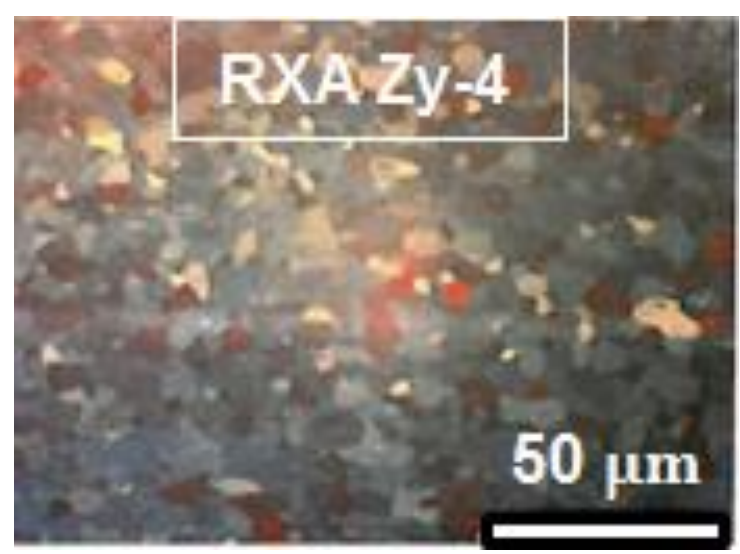

Equiaxed and recrystallized grains 


\section{- Impact of an external stress on the c-loops}




\section{Specific and appropriate samples}

- Sampling for both experiments allowed a large variability of c-axis orientation with respect to the direction of the applied loading

\section{In-situ tests}

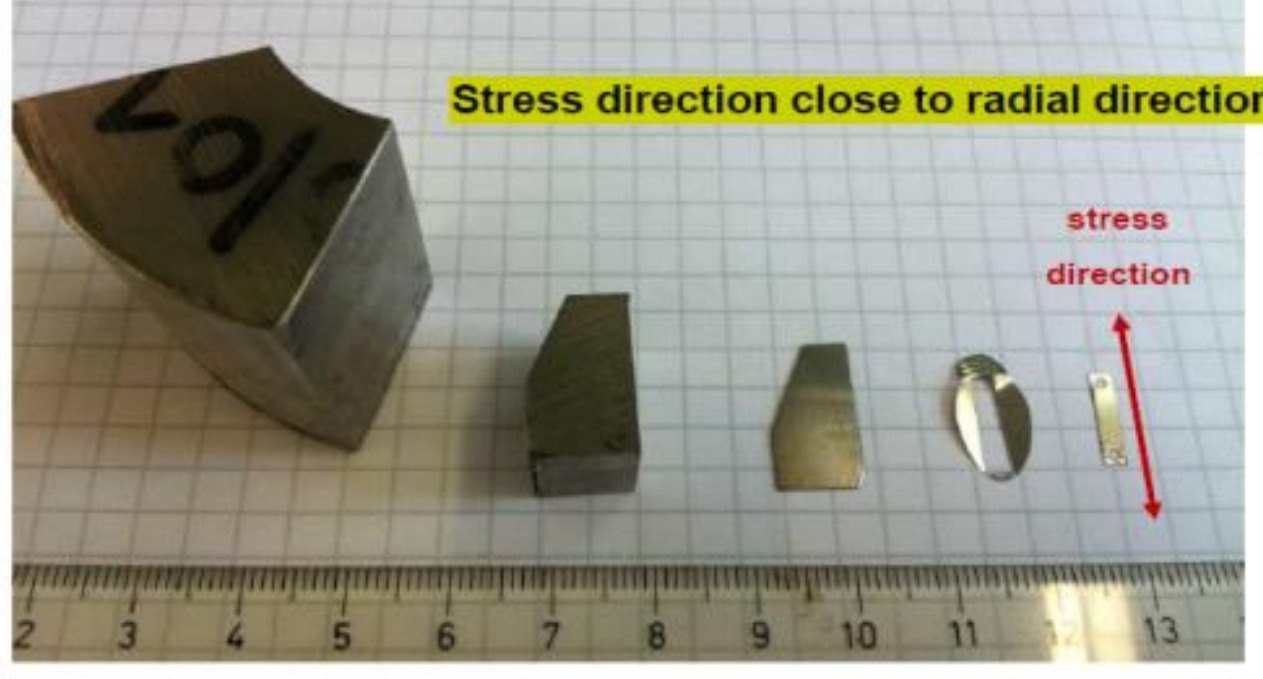

Bending experiments

Stress direction close to the transverse direction (TREX) 


\section{In-situ tensile tests under ion irradiation}

$\checkmark 1 \mathrm{MeV} \mathrm{Kr}^{2+}$ ion irradiation at $573 \mathrm{~K}$

The entire thickness of the sample is irradiated

\section{Experimental procedure}

$>$ Heating to $300^{\circ} \mathrm{C}$

- Stress applied at the beginning of the irradiation Stretching of the sample until dislocation glide occurs

$\rightarrow$ yield strength reached

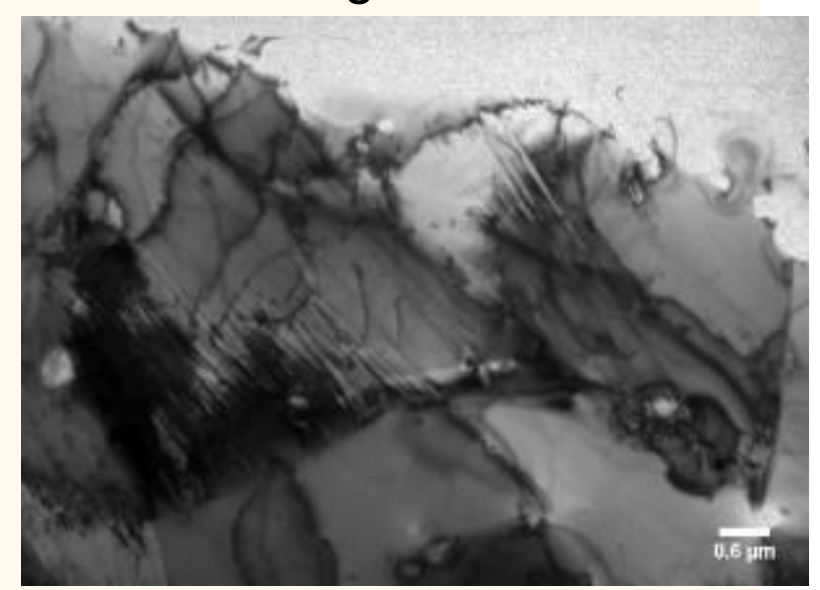

- Irradiation with in-situ TEM

Straining sample

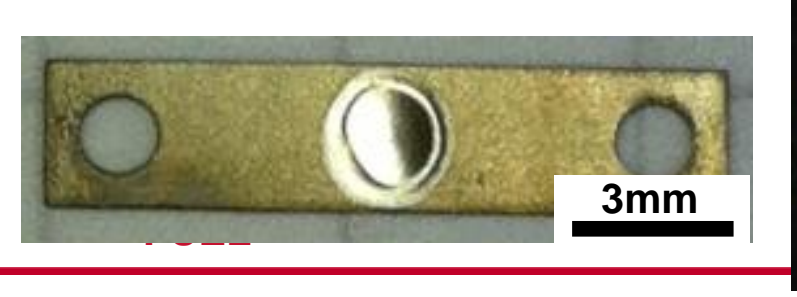

Heating /Straining stage

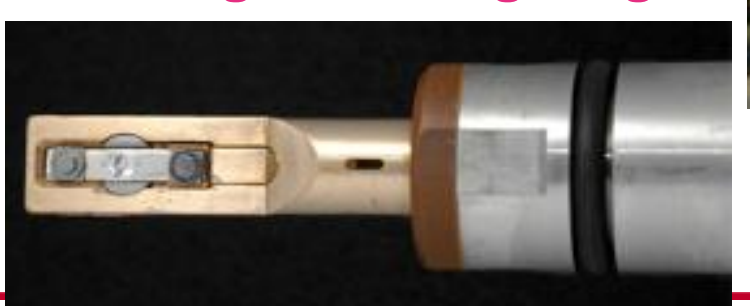

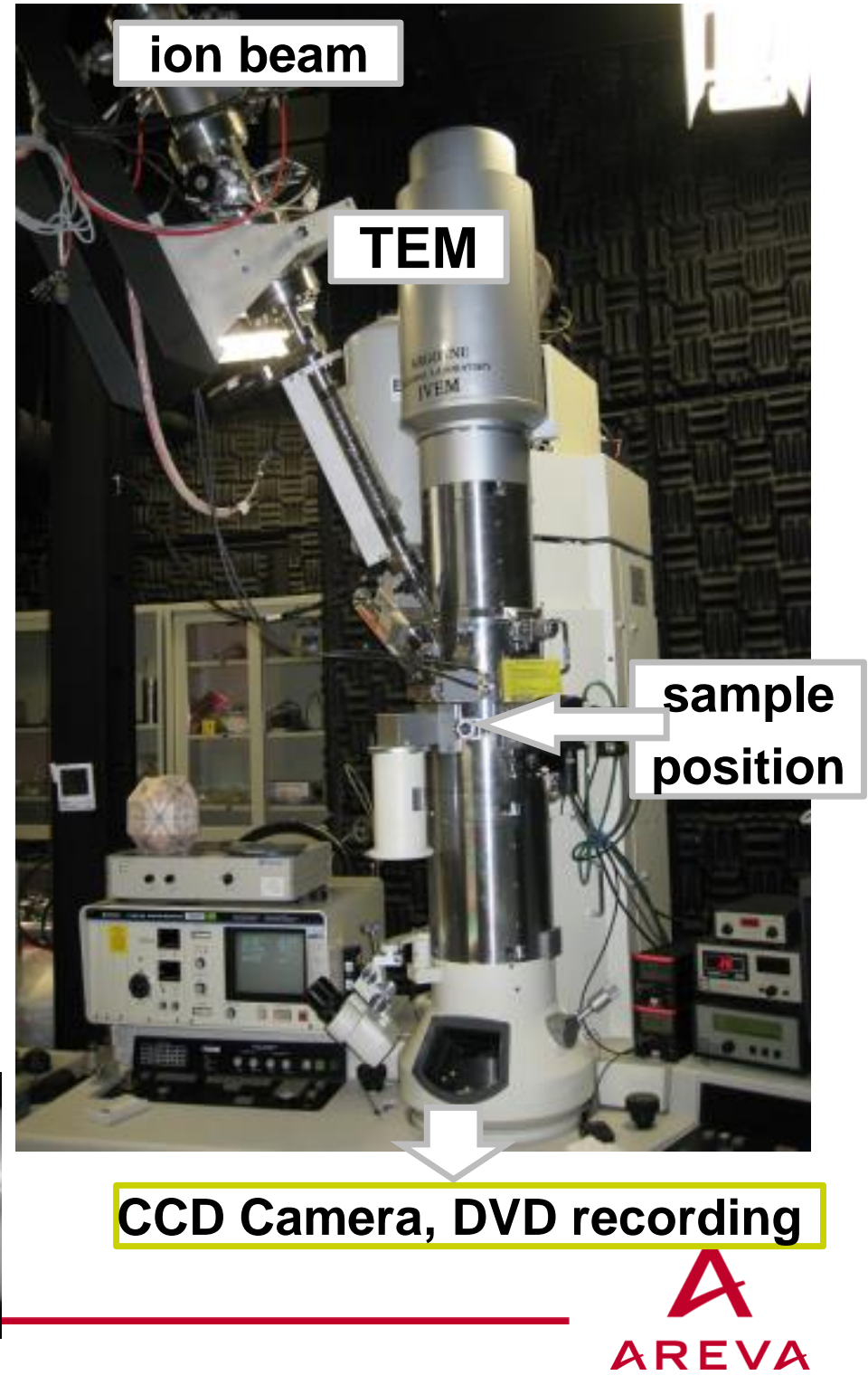




\section{Impact of tensile stress on $<\mathrm{c}>$-loops: sample at YIELD STRENGTH}

Zircaloy-4 at yield strength, 4 adjacent grains, different orientations

Stress level: $256 \mathrm{MPa}$

$\checkmark$ Final dose: 25-27dpa (SRIM calculation with "full damage cascades" option)

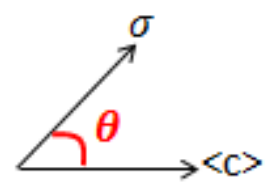

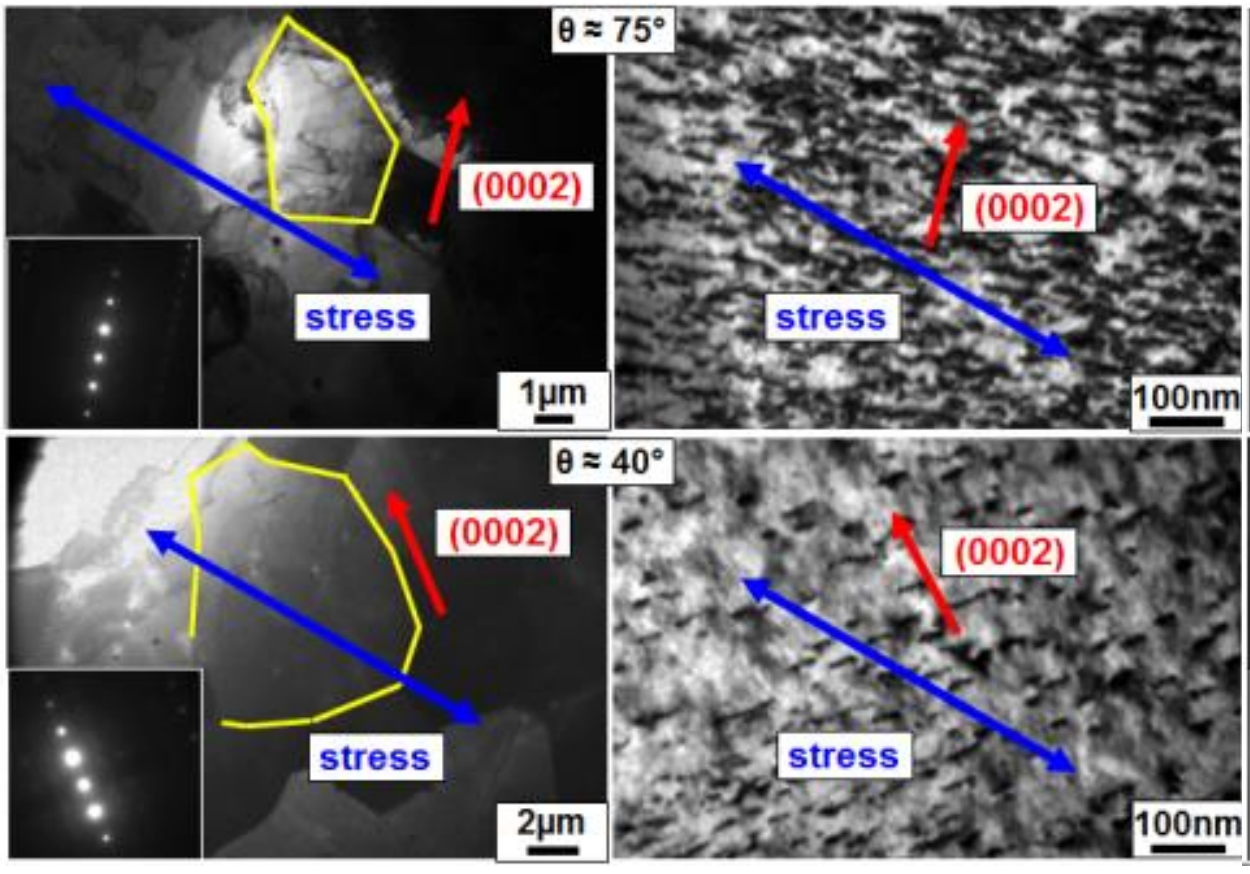

Numerous <c>-loops in grains with $<$ c $>$ axis far from the tensile direction FUEL

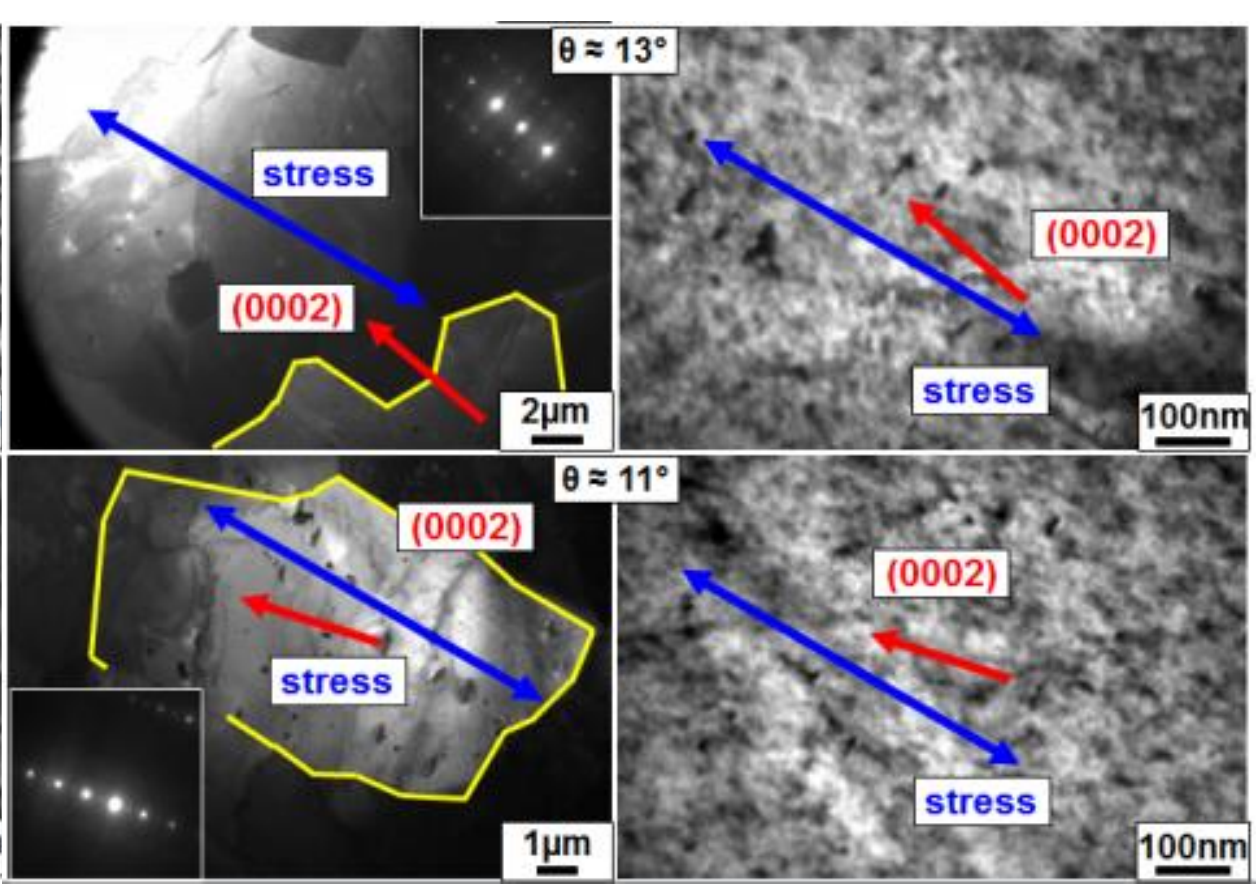

Few $<$ c $>$-loops in grains with $<$ c $>$-axis close to the tensile direction 


\section{Impact of tensile stress on $<c>-$-loop linear density and diameter}
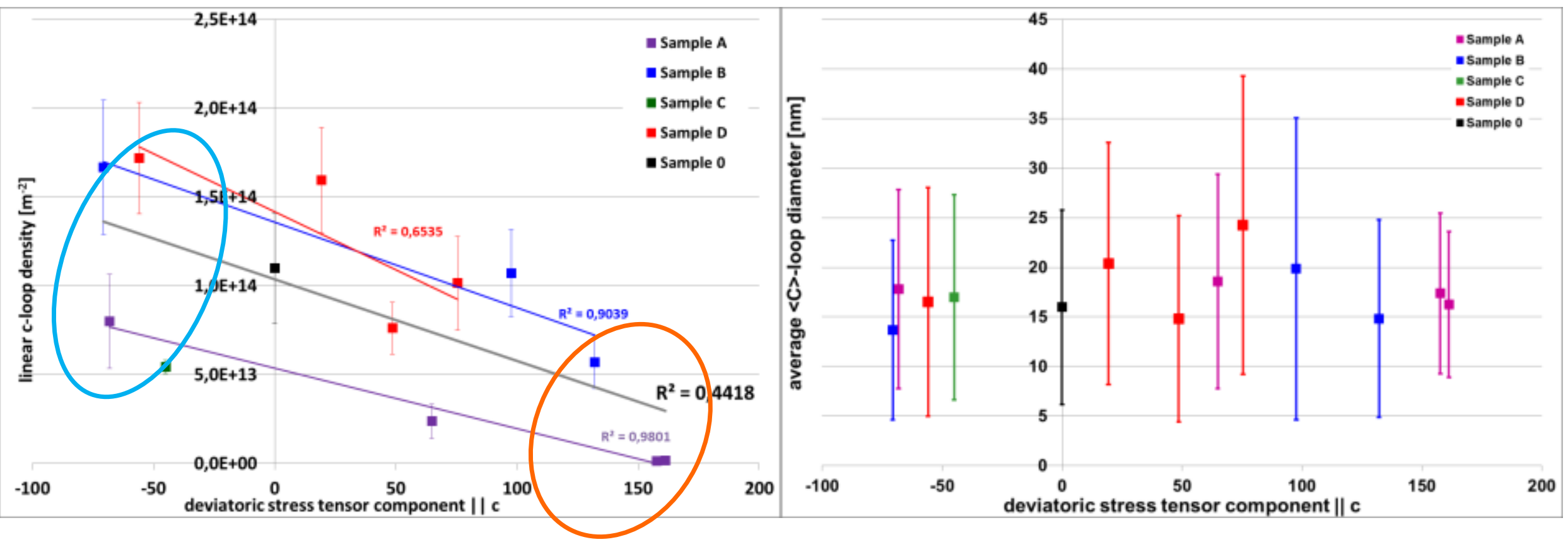

Tensile stress $\|\langle c\rangle$ : lower density

Tensile stress $\perp<c\rangle$ : higher density

Within each sample but for few grains, the <c>-loop density shows a significant decrease with increasing deviatoric stress tensor component in the c-direction

Combining the data from all samples, the slope remains the same but dispersion is observed

The ${ }_{E}<C>$ loop average diameter is not dependent on the deviatoric stress tensor component in the e-direction 


\section{BENDING EXPERIMENTS under ion irradiation}

$600 \mathrm{keV}$ Zr ion irradiation at $573 \mathrm{~K}$

Damage created on a thin layer of $300 \mathrm{~nm}$ depth

$\checkmark$ Irradiation campaign in two steps

Stress applied when c-loops are already

1

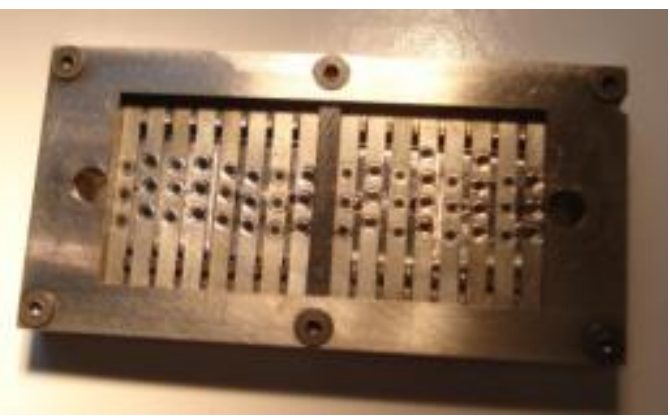

Pre-irradiation $\sigma=0$ up to $4.1 \mathrm{dpa}$

(Full Cascades

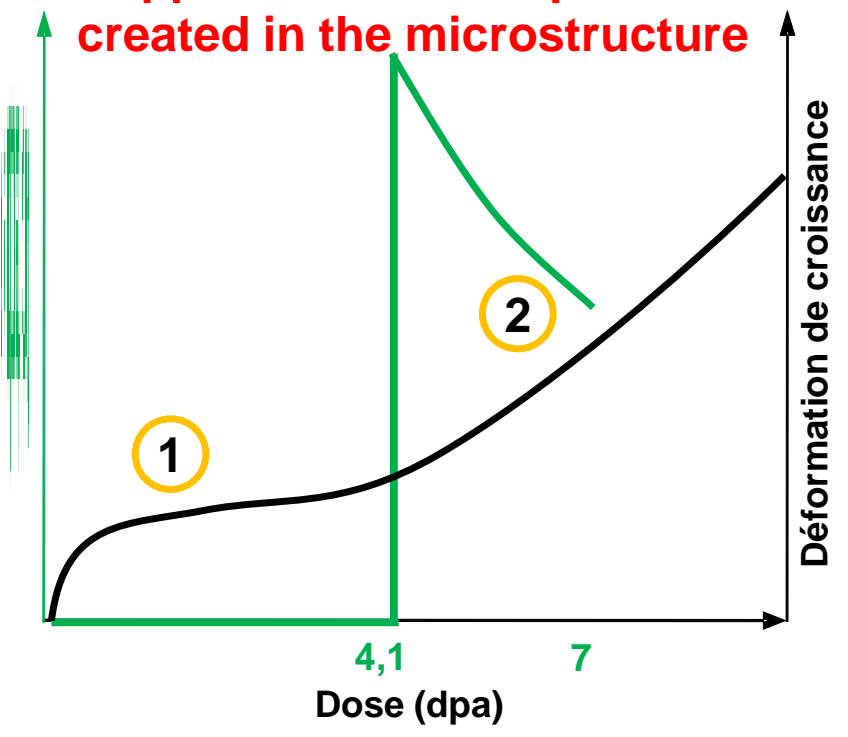

ARAMIS facility at CSNSM Orsay

(2)

Control samples

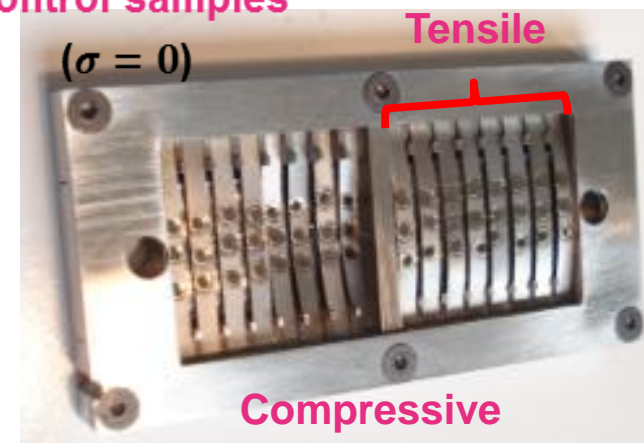

Two mechanical loadina

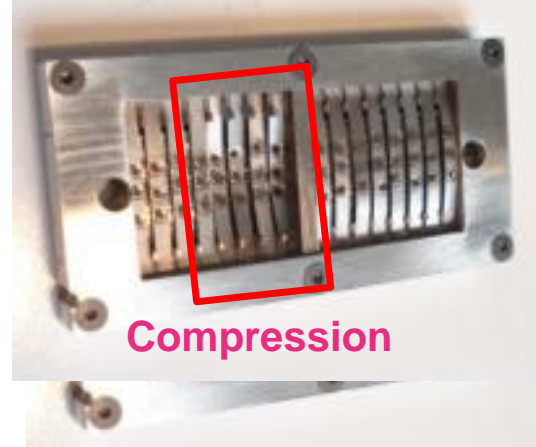

Bending

FUEL

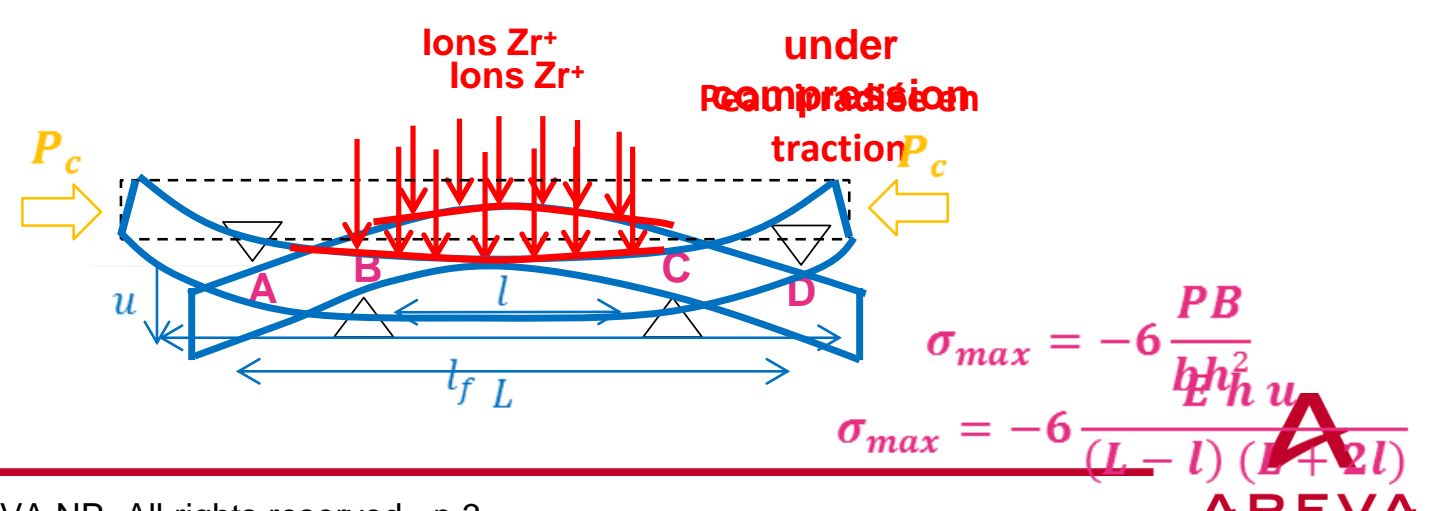




\section{Impact of tensile stress on <c>-loop MICROSTRUCTURE}

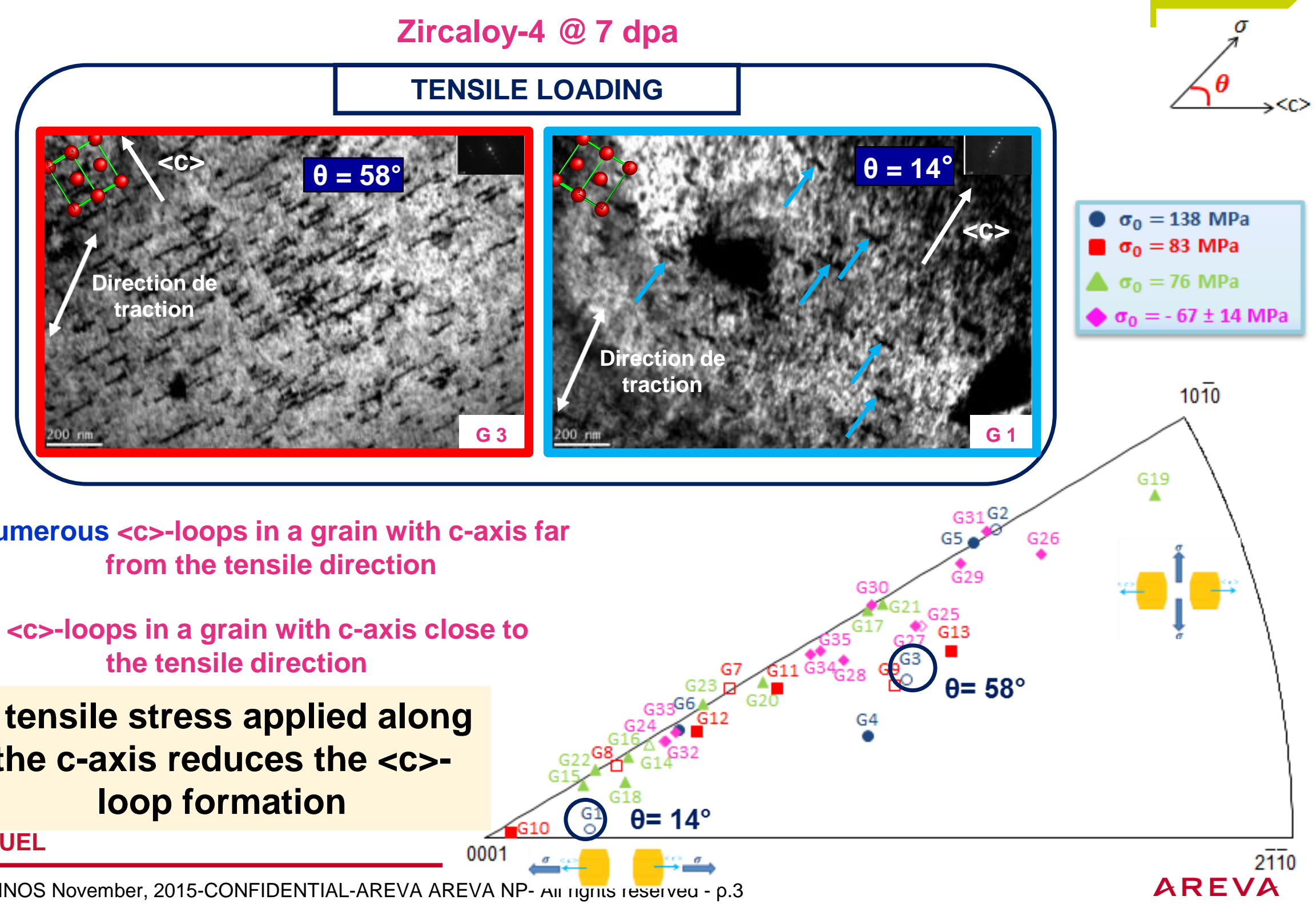


Not significant effect of stress on $<\mathrm{c}>$ loops microstructure and density

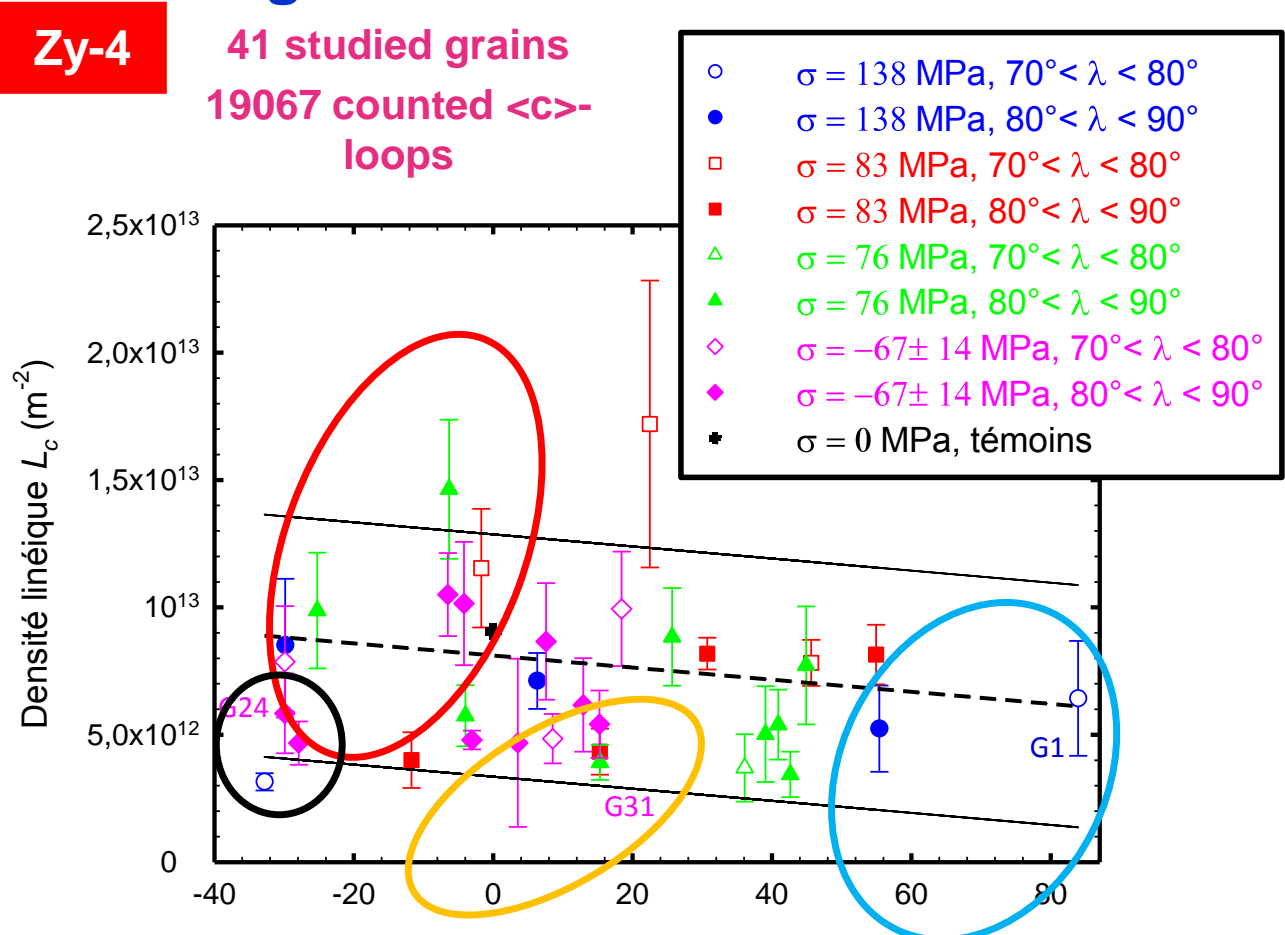

Composante suivant $<c>$ du déviateur du tenseur des contraintes (MPa)

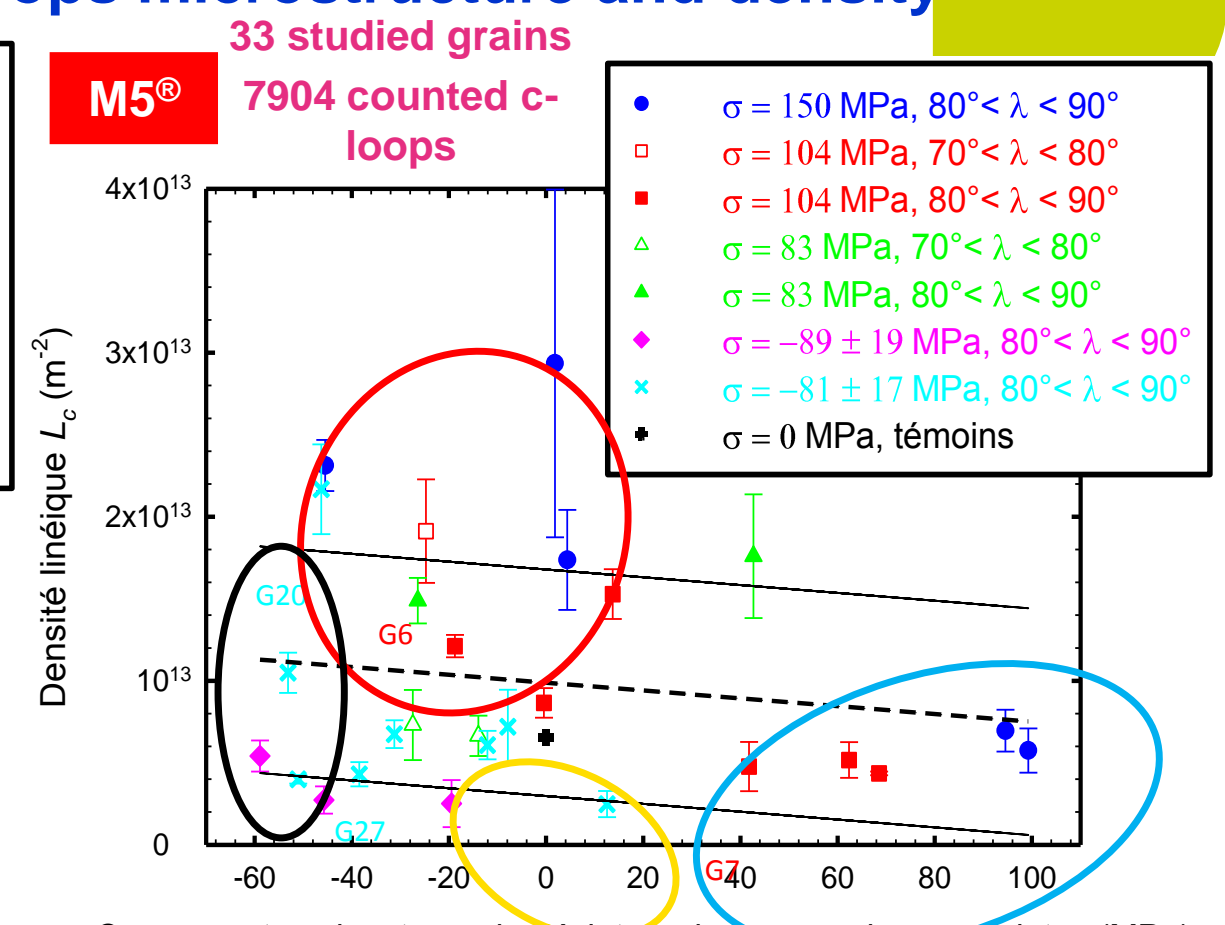

Composante suivant $<\mathrm{c}>$ du déviáteur du tenseur des sontraintes (MPa)

$\square<c>-l o o p$ size distribution quite homogeneous in each grain

$\square$ Large statistical study $\rightarrow$ dispersion from grain to grain

Tensile stress $\|<\mathrm{C}\rangle$ : low density

Tensile stress $\perp<\mathrm{c}\rangle$ : slightly higher density

Compressive stress $\perp<\mathrm{C}\rangle$ : low density

$\mathrm{Zy}-4: L_{v}=-2,37 \times 10^{10} \sigma_{D}{ }^{<c>}+8,11 \times 10^{12}\left(\mathrm{~m}^{-2}\right)$

M5 $5^{\oplus:} L_{v}=-2,38 \times 10^{10} \sigma_{D}^{<c>}+9,88 \times 10^{12}\left(m^{-2}\right)$

Compressive stress $\|<\mathrm{C}\rangle$ : slightly higher density

$>$ In agreement with SIPA mechanism

$>$ Ngt significant effect of stress on $<\mathrm{c}>$ loops microstructure and density 


\section{Conclusions on stress impact}

\section{Questions}

Q1: Effect of stress on <c>-loops density ?

Q2: Coupling between irradiation free growth and axial creep ?

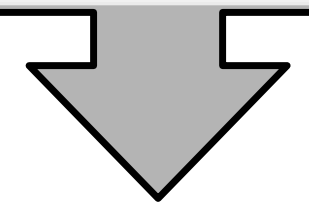

1:Low impact of tensile and compressive stress $<\mathrm{c}>$ loops microstructure

2: Low coupling between growth breakaway and axial creep at grain scale

$\square$ Evolution of c-loops density with stress in agreement with SIPA 


\section{Impact in-service hydrogen pick-up on the c-loops}


Toward a better understanding of the hydrogen impact on the radiation induced growth of zirconium alloys

How in-service hydrogen pick-up could influence the growth acceleration?

What is the impact of a pre-hydriding on the $<\mathrm{c}>$ loop microstructures?

L. Tournadre et al.

\section{Neutron irradiation simulated by Protons}

Michigan Ion Beam Laboratory FOR SURFACE MODIFICATION AND ANAL YSIS

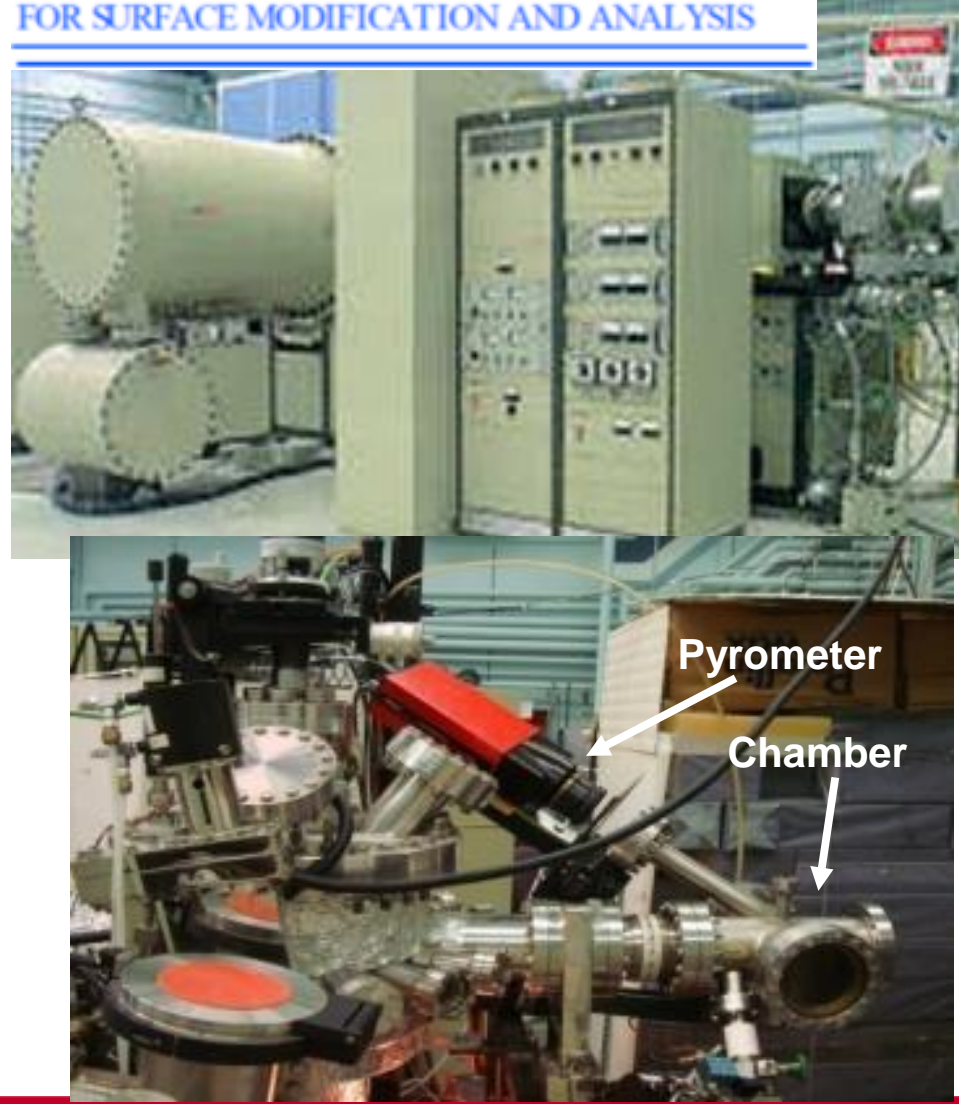

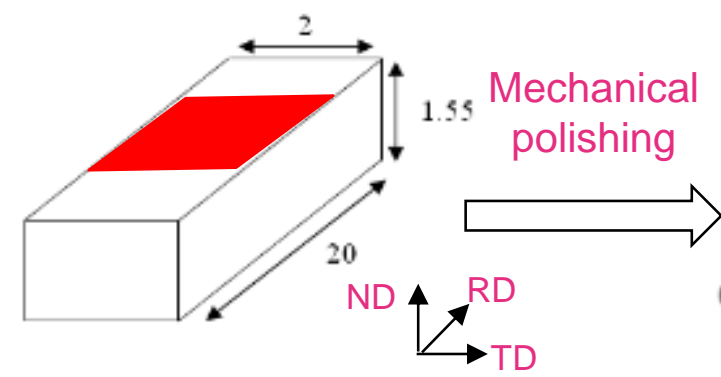

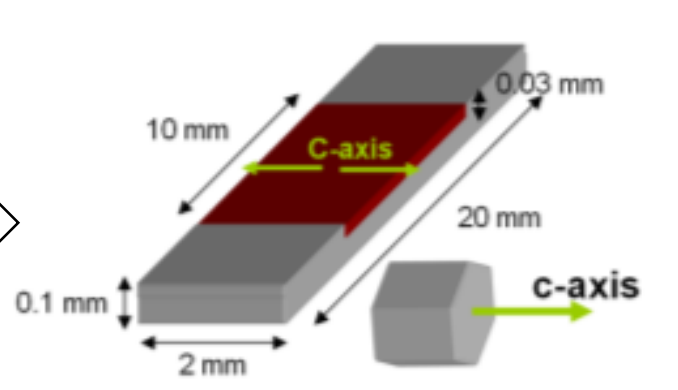

12.
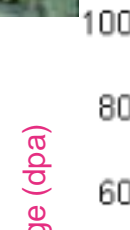

ฮั

Thin foil
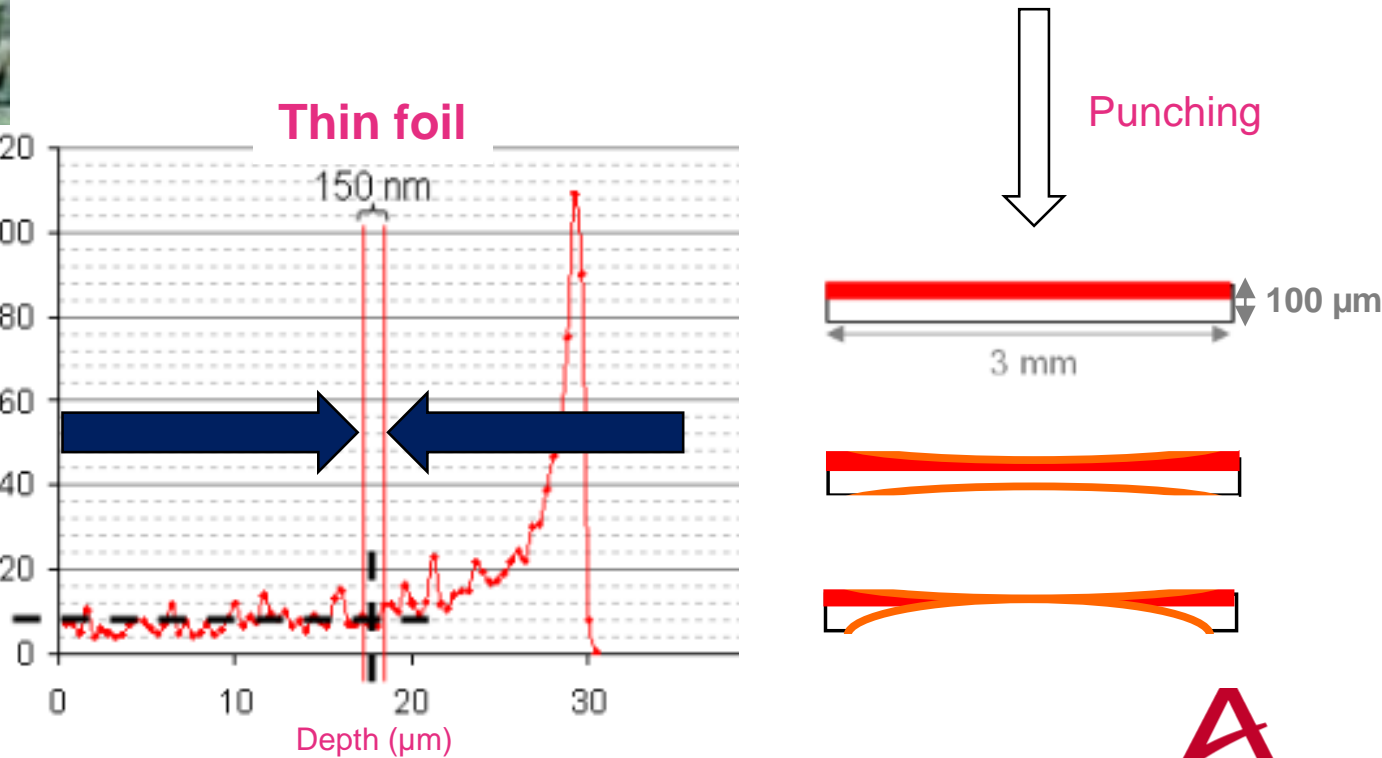

$3 \mathrm{~mm}$
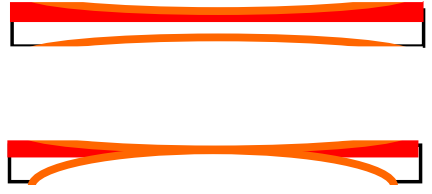

4

AREVA 
Hydrogen in the matrix increases the $<c>$ loop density

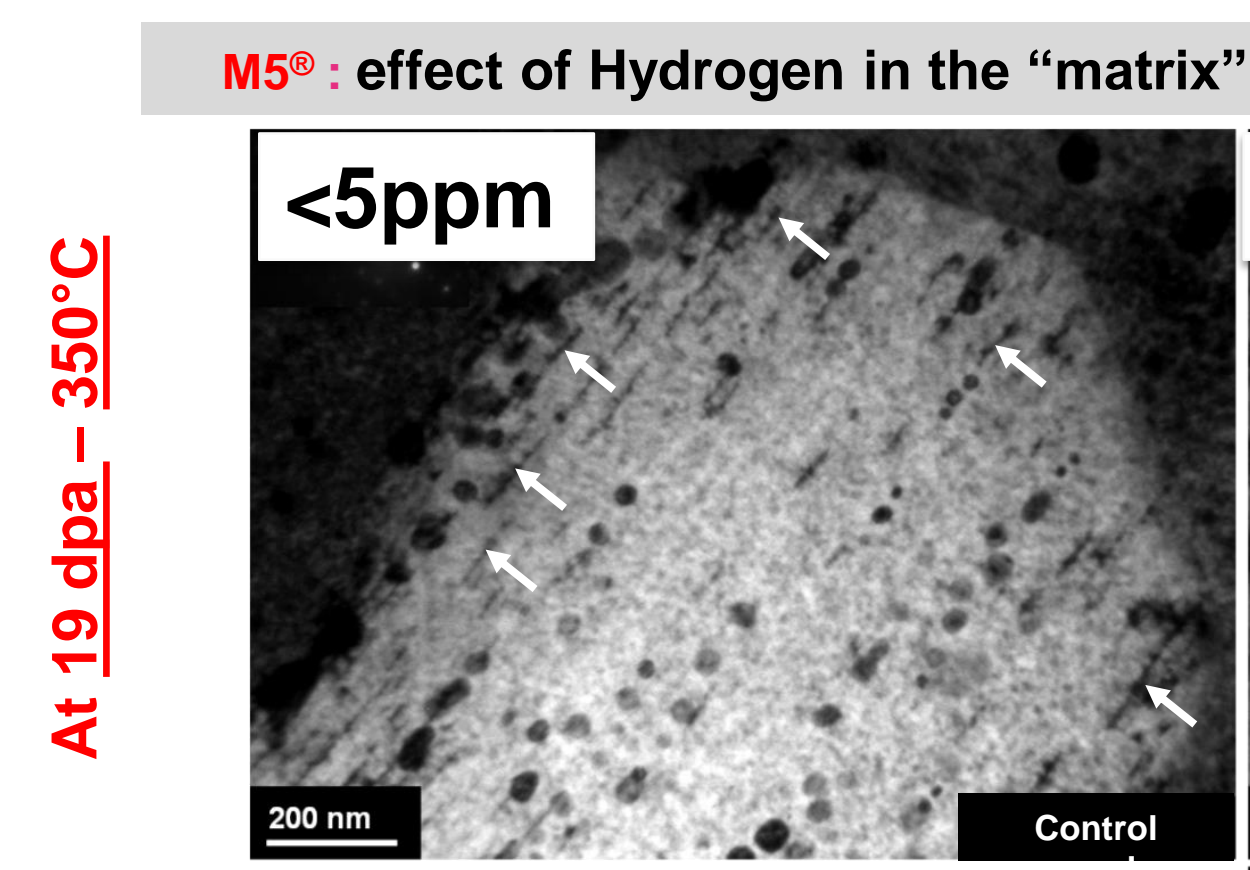

\section{In pre-hydrided samples:}

"(far from precipitated hydrides)

$\Rightarrow$ C-loop microstructures more homogeneous

$\Rightarrow$ Density slightly higher

Also observed at $8.1 \mathrm{dpa}$ and $\mathbf{1 2 . 5} \mathrm{dpa}$

\section{0ppm}

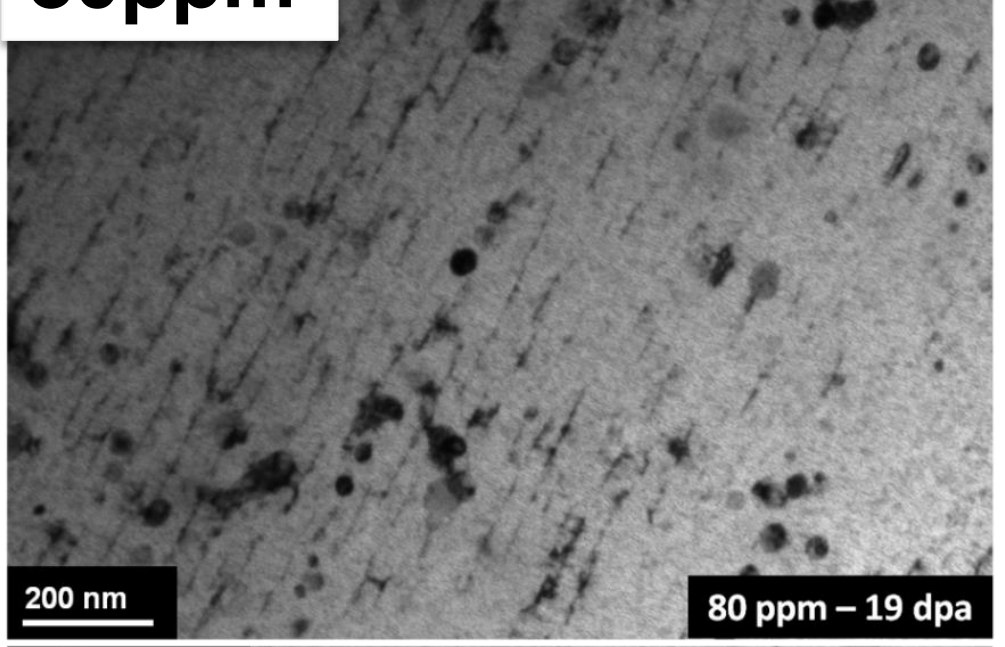

\section{0ppm}


Locally high $<c>$ loop densities at the vicinity of precipitated hydrides

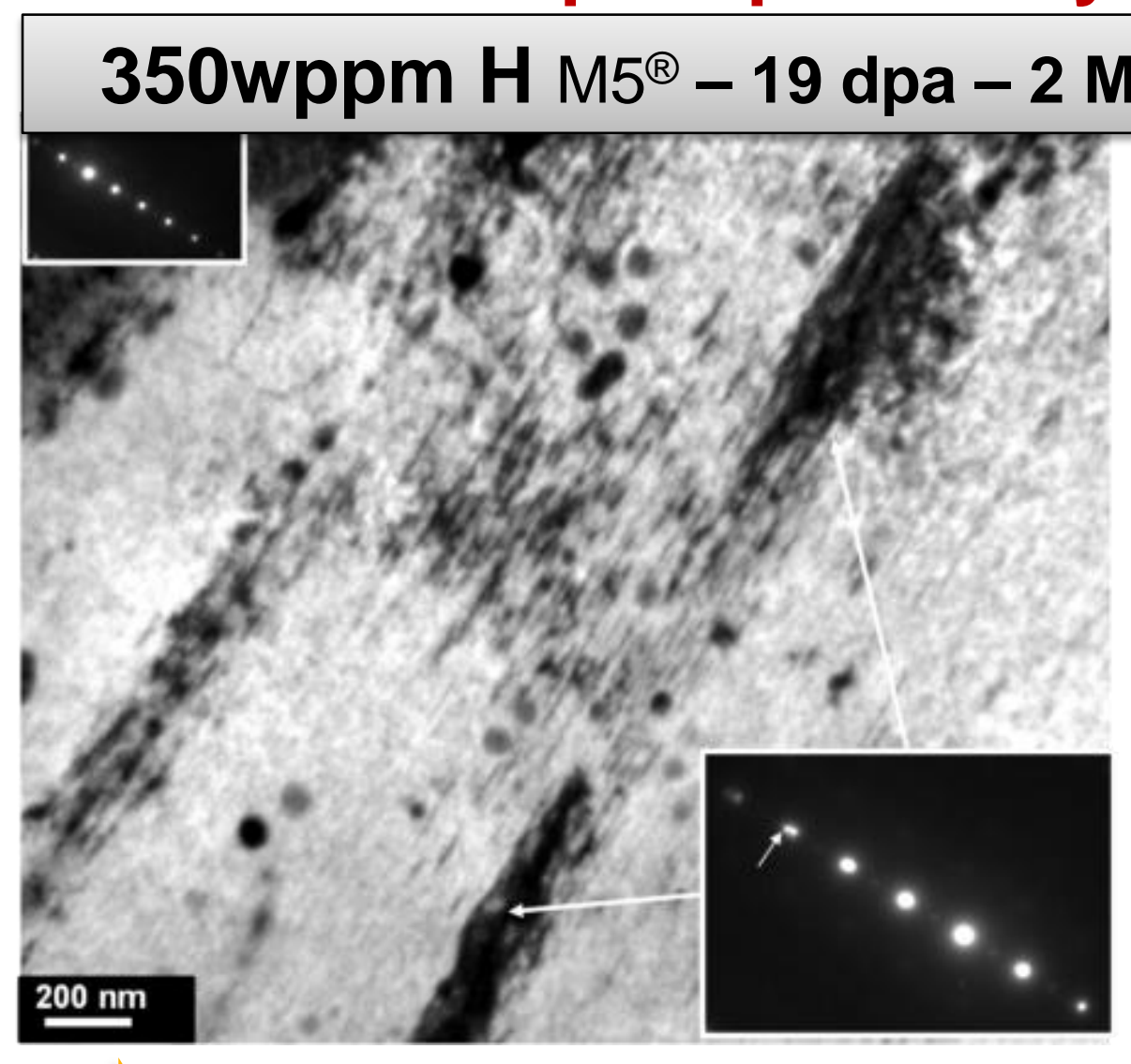

$\Longrightarrow$ Locally high <c> loop densities
eV proton irradiations $-623 \mathrm{~K}$

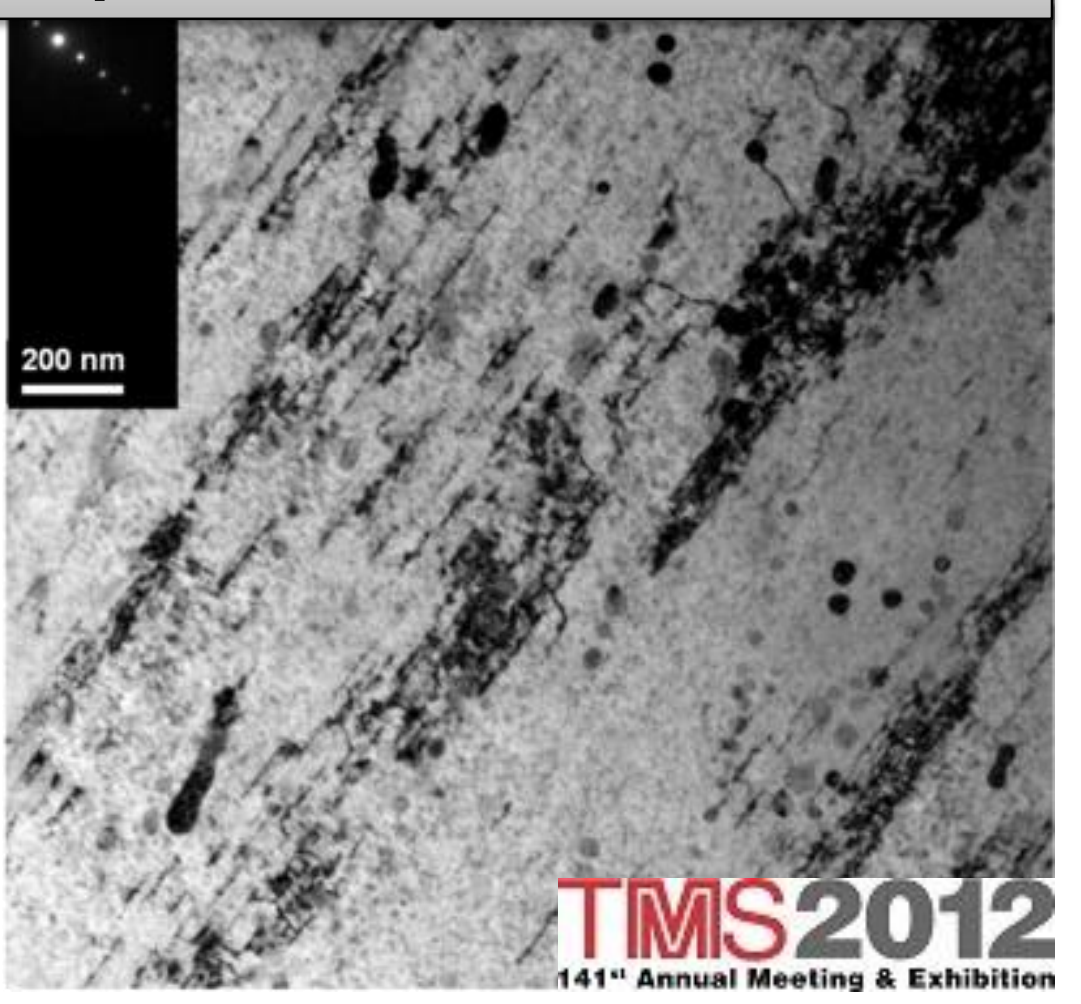

L. Tournadre et al.

-In some specific areas, $<c>$ loop gathered as "bundles"

Also observed at 8.1 and $12.5 \mathrm{dpa}$

FUEL 


\section{Hydrogen atoms in solid solution enhances the nucleation / growth of c-loops}

$$
\underline{M 5^{\circledR}-19 \mathrm{dpa}-350^{\circ} \mathrm{C}}
$$

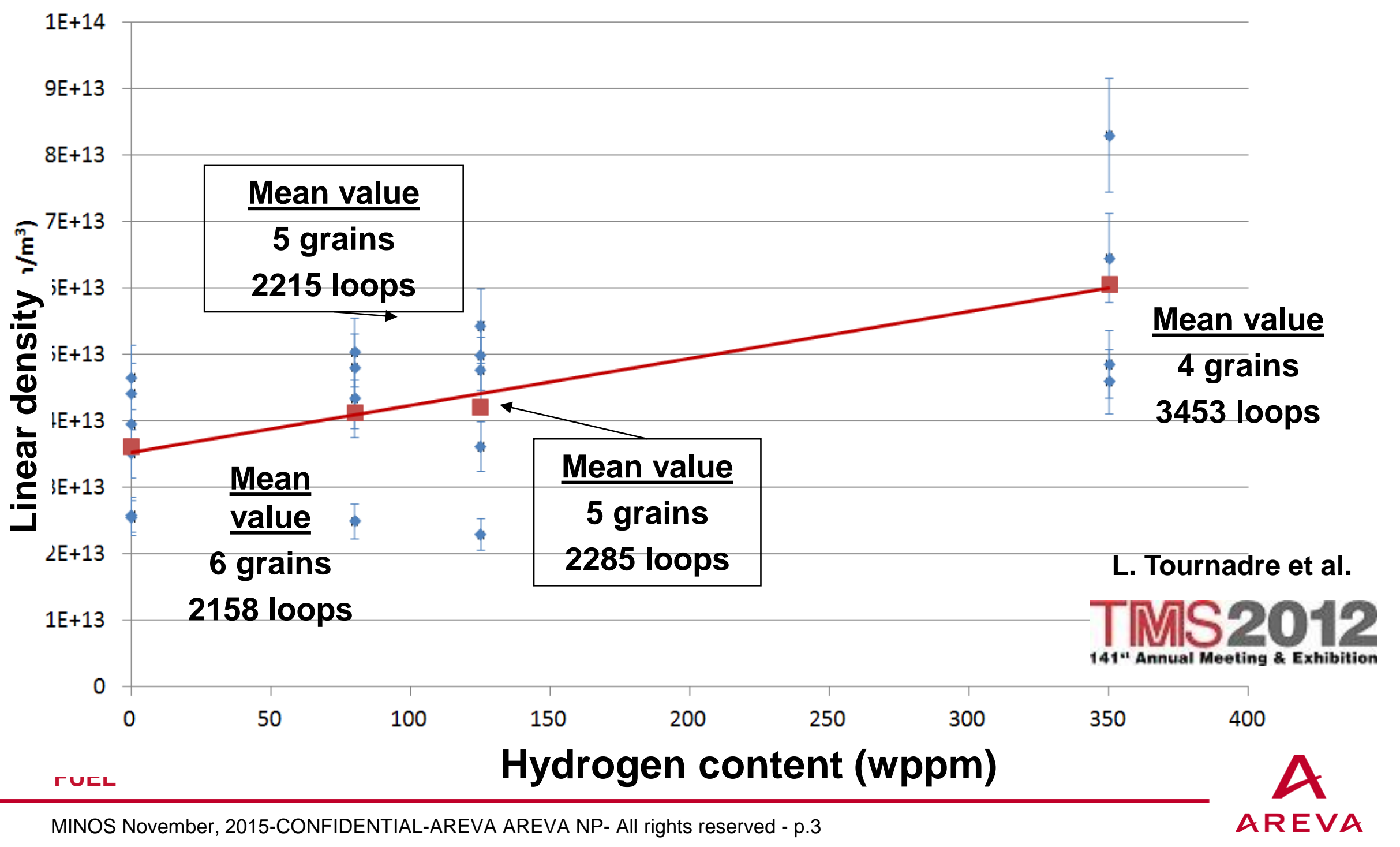


L. Tournadre et al.

\section{How hydrogen could influence $<c>$ loop microstructure?}

- Hydrogen atoms in solid solution ( $\sim 100 \mathrm{wppm}$ at $623 \mathrm{~K}$ in non-irradiated materials) enhances the nucleation and growth of c-loops

Homogeneous distribution and density slightly higher in the "matrix"

- Locally high $<\mathrm{c}>$ loop densities at the vicinity of precipitated hydrides

Hydride dissolution: a source of hydrogen in solid solution

$<\mathrm{C}+$ a $>$ remaining dislocations after dissolution: a nucleation site for $<\mathrm{c}>$ loops

$<c>$ loop "bundles"

Two main mechanisms ?:

- trapping of hydrogen atoms in solid solution on $<c>$ loop nuclei

- $<\mathrm{C}+\mathrm{a}>$ remaining dislocations after dissolution

FUEL 


\section{Future prospects deformation modeling under flux}

\section{'Macroscopic model'}

with micro internal variables

\section{'Polycristaline model'}

\section{'Ab-initio' (atomic scale)}




\section{Conclusion}

$\mathrm{Zr}+$ or $\mathrm{Kr}+$ lons and Protons irradiations :

produce relevant data in much shorter time than neutron (hours/days or weeks / years)

create c-component dislocation loops

- representative of neutron damage (mainly protons)

- An excellent tool :

to understand the breakaway growth of recrystallized Zr-based alloys

to model FA irradiation growth

Other applications (corrosion, ...)?

\section{Thank you for your attention}




\section{Back-up}

FUEL 


\section{Stress Induced Preferential Absorption Mechanism} (SIPA)

Influence of the applied stress on the elastic interaction energy between the point defects and the dislocation loops

Modification of the capture efficiency of Self-Interstitial Atom (SIA) by a dislocation loop

$$
Z_{S I A}^{l o o p}(\sigma)=Z_{0}+C \sum_{i, j} n_{i} \sigma_{i j}^{s} n_{j}
$$

W.G. Wolfer, Journal of Nuclear Materials, 90 (1980) 175

For a vacancy <c>-lpop located in the basal plane

$$
Z_{i}^{l}(\sigma)=Z_{0}-\frac{1}{3} C \sigma
$$

Tensile stress applied along the c-

$$
Z_{i}^{l}(\sigma)=Z_{0}+\frac{2}{3} C \sigma_{0}
$$
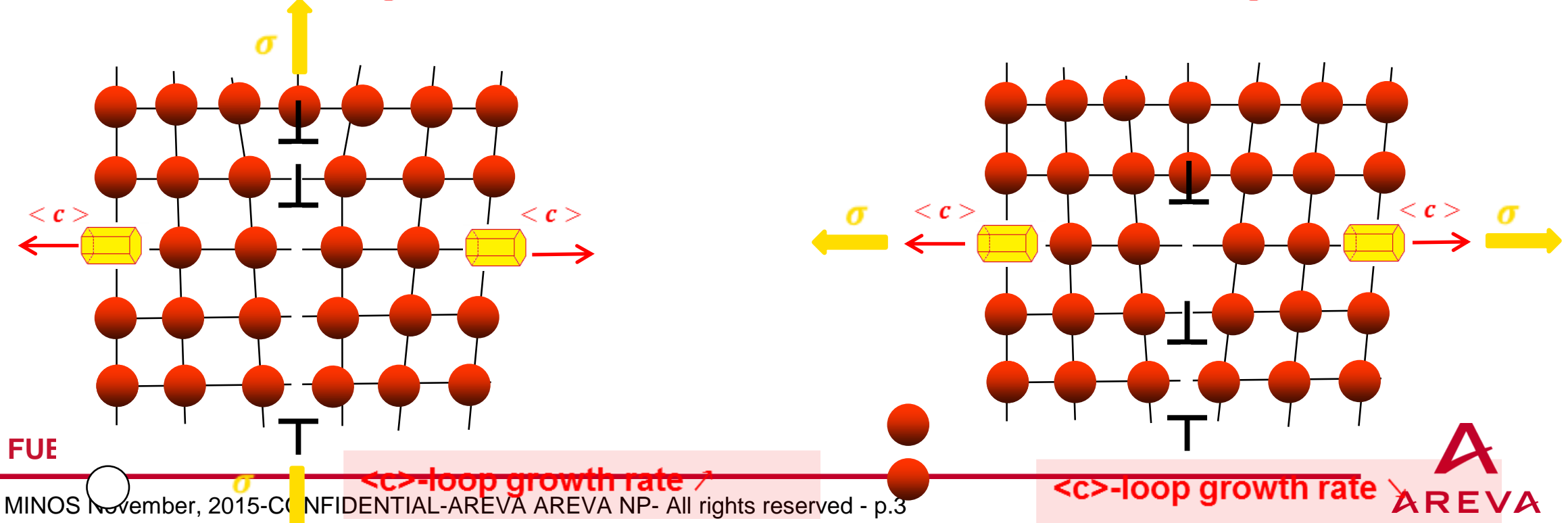
Any reproduction, alteration, transmission to any third party or publication in whole or in part of this document and/or its content is prohibited unless Company Name has provided its prior and written consent.

This document and any information it contains shall not be used for any other purpose than the one for which they were provided. Legal action may be taken against any infringer and/or any person breaching the aforementioned obligations. 